\title{
Jane Engeldinger, MD
}

\section{Articles:}

Segre LS, Brock RL, O'Hara MW, Gorman LL, Engeldinger J. Disseminating perinatal depression screening as a public health initiative: a train-the-trainer approach. Matern Child Health J. 2011 Aug;15(6):814-21. PubMed PMID: 20640494; PubMed Central PMCID: PMC3132246. http://dx.doi.org/10.1007/s10995-010$\underline{0644-1}$

Nylen KJ, O'Hara MW, Engeldinger J. Perceived social support interacts with prenatal depression to predict birth outcomes. J Behav Med. 2012 Jun 19. [Epub ahead of print] PubMed PMID: 22710981.

http://dx.doi.org/10.1007/s10865-012-

$\underline{9436-y}$ 